\title{
Comparison of twenty three nebulizer/compressor combinations for domiciliary use
}

\author{
E.C. Smith*, J. Denyer**, A.H. Kendrick*
}

Comparison of twenty three nebulizer/compressor combinations for domiciliary use. E.C. Smith, J. Denyer, A.H. Kendrick. @ERS Journals Ltd 1995.

ABSTRACT: We have assessed the physical and dynamic characteristics of 23 home jet nebulizer/compressor combinations currently available in the UK and Europe.

The combinations were evaluated in terms of pressure-flow characteristics, aerosol mass distribution, volume output, electrical costs, and sound level. In addition, we determined the effect of nebulizer fill volume on aerosol mass distribution and volume output. One nebulizer was used with six different compressors, and four compressors were tested with three different nebulizers.

The pressure-flow relationships showed a wide variation between models, as did flow-rate at the nebulizer (range 3.0-8.0 L $\cdot \mathrm{min}^{-1}$ ). The mean \pm SD volume nebulized after 10 min using an initial fill volume of 2.5 and $5.0 \mathrm{~mL}$ was $46 \pm 9$ and $34 \pm 12 \%$, respectively. The mass median aerodynamic diameter (MMAD) over a 5 min nebulization ranged 2.6 to $10.2 \mu \mathrm{m}$. Nine of the nebulizations produced an MMAD of less than $5 \mu \mathrm{m}$ at both fill volumes. Changing nebulizer/compressor combinations affected flow rate, MMAD and volume output. Sound levels varied between models. Running costs were low, with all using less than $\mathbf{7 4}$ kilowatt hours of energy per year.

We conclude that there is a wide variation in performance of nebulizer/compressor combinations for use with nebulized bronchodilators. Correct matching of the nebulizer/compressor is seen to be important to ensure optimum performance. We recommend that: 1) manufacturers of nebulizers provide information on the required flow rate at the nebulizer to produce the required MMAD, and the percentage of aerosol/mass contained in particles under $5 \mu \mathrm{m}$; and 2) suppliers of nebulizer/compressor systems match the combinations more carefully to achieve optimal delivery of the nebulized drug to the patient, and that users should use recommended combinations.

Eur Respir J., 1995, 8, 1214-1221.

\author{
*Respiratory Dept, Bristol Royal Infirmary, \\ Bristol, UK. **Medic-Aid, Pagham, Sussex, \\ UK. \\ Correspondence: E.C. Smith \\ Respiratory Dept \\ Bristol Royal Infirmary \\ Bristol \\ UK \\ Keywords: Inhalation devices \\ nebulizers \\ respiratory therapy
}

Received: January 131993

Accepted after revision March 141995
Portable nebulizer/compressors are increasingly being used by asthmatics and patients with chronic obstructive airway disease as part of their domiciliary treatment using inhaled $\beta_{2}$-agonist and anticholinergic drugs. Since the last published comparison [1], many new nebulizers have become available, or previous models updated. Furthermore, in the United Kingdom, the National Asthma Campaign (NAC) (London, UK) provides a list of recommended nebulizer/compressor combinations for potential purchasers. Those not on the list are generally regarded as unsuitable. We have compared 23 nebulizer/compressor combinations, some of which are on the list, to determine their physical and dynamic characteristics.

\section{Methods}

The manufacturers of all compressors known to the authors were approached and asked to supply a complete system of nebulizer, compressor, tubing, face mask and instruction manual.

\section{Physical characteristics}

The maximum dimensions of each compressor were determined using a ruler to the nearest $1.0 \mathrm{~mm}$. Mass was measured using scales (Seca, Model 750) accurate to the nearest $0.1 \mathrm{~kg}$. The sound level $(\mathrm{dBC})$ of each combination was determined at a distance of one metre, using a sound level meter (Dawe Instruments, Type D$1422 \mathrm{C}$ ), the value obtained being to the nearest $1 \mathrm{~dB}$. The meter was calibrated at a single level of $114 \mathrm{~dB}$ at $1 \mathrm{kHz}$ (Dawe Acoustic calibrator D1411E, Dawe Instruments).

\section{Dynamic characteristics}

The pressure-flow characteristics were determined using a rotameter (Platon Flow Control, Gapmeter GTLK) and a pressure transducer (Validyne MP45) in series. The transducer was linear over its working range, and the 
system was calibrated using a water manometer before each series of experiments. The output of the transducer was displayed on a X-Y recorder (Bryans 26700 Model A4). Free flow was recorded as the maximum flow rate $\left(\mathrm{L} \cdot \mathrm{min}^{-1}\right)$ the compressor developed at zero resistance. Maximum static pressure $(\mathrm{kPa})$ was recorded as the maximum pressure that the compressor could develop at zero flow. This was achieved by closing the needle valve of the rotameter fully. A pressure-flow curve was obtained for each combination by adjusting the needle valve of the rotameter to different flow rates, from free flow, to zero flow, and the corresponding pressure recorded.

The pressure and flow-rate generated at the nebulizer were estimated by replacing the flow meter with the nebulizer and recording back pressure using a fill volume of 2.5 and $5.0 \mathrm{~mL}$ sterile water. The flow rate corresponding to the measured back pressure was obtained from the pressure-flow curve.

The volume output of the nebulizer was estimated at 2, 510,15 and $20 \mathrm{~min}$ for each combination using 2.5 and $5.0 \mathrm{~mL}$ starting volume of sterile water. For each assay, the nebulizer was dried and its dry mass recorded to the nearest $0.01 \mathrm{~g}$ using scales (Ohaus, CT200), which had a two point calibration performed at regular intervals throughout the studies. The required volume of sterile water was pipetted (Macro Transferpettor) into the nebulizer cup and the mass of the cup plus water recorded. The nebulizer/compressor was then run for the required length of time, at the end of which the mass of the nebulizer cup and water remaining was measured. Estimates of volume output at the different times were made in a random order.

\section{Determination of aerosol mass distribution}

The size distribution of the aerosol mass generated by each of the combinations was determined from laser diffraction (Malvern, Master Sizer MS20), the analysis of particle size distribution into the volume distribution being based upon the Mie Theory. The focal length was 100 $\mathrm{mm}$, giving a measurement range of $0.5-170 \mu \mathrm{m}$. Prior to use, the laser beam was automatically aligned with the collector and background readings taken, these being subtracted from each of the measurements subsequently made. Each measurement is the average taken of 200 individual measurements made over approximately $5 \mathrm{~s}$. To avoid the effect of fluctuations in natural daylight affecting this background reading, all measurements were made in a darkened room.

Sterile water was used in all studies. The aerosol produced was presented to the laser in a fixed configuration using a specially designed presentation module (Medic-Aid, UK). This ensures that the droplets are carried in such a manner that they are not affected by contact with ambient air, and does not change the particle distribution between the nebulizer and the point at which it is presented to the laser. Since the density of water is essentially 1.0, the volume distribution which the laser produces can be regarded as the mass distribution. Particles were presented to the laser beam in a horizontal mode to reduce the effects of gravity on the measurements.
The nebulizer was filled with 2.5 and $5.0 \mathrm{~mL}$ water and nebulized for $5 \mathrm{~min}$. Throughout this nebulization period, the aerosol mass distribution was recorded at 1 min intervals. For two compressors (Aeroneb Standard and Porta-Neb 50) measurements were made over a longer period of $10 \mathrm{~min}$ to determine the variation of aerosol mass distribution with time.

From the aerosol mass distribution, as obtained from the laser diffraction measurements, the mass median aerodynamic diameter (MMAD) was obtained. This is the particle diameter about which $50 \%$ of the mass of the aerosol particles is distributed. The percentage of aerosol mass less than $5 \mu \mathrm{m}$ was also obtained from this plot.

\section{Yearly electrical costs}

The yearly electrical costs of the compressor were calculated on the basis of four 15 min nebulizations daily for one year. The power rating (Watts) of the compressor was used to calculate the energy consumed (kilowatt hours) for nebulization.

\section{Different nebulizer/compressor combinations}

Four compressor units were each supplied with three different nebulizer units. For each combination, the above measurements were made to compare any differences in performance. Performance differences were also compared for one nebulizer (Cirrus) that was available with six different compressors.

\section{Data analysis}

Comparison of measurements at different times was made using paired t-tests, whilst to compare the variation in MMAD over time, analysis of variance (ANOVA) was used. Linear regression and ANOVA as applied to regression was used to determine relationships between a number of measurements. To compare equations obtained at different fill volumes, analysis of covariance was used to assess any differences in slope and intercept. Results are given as mean \pm SD.

\section{Results}

\section{Physical characteristics}

The physical characteristics of the compressors, the nebulizer chambers supplied, and estimated annual energy consumption are given in table 1 . The overall dimensions, mass, sound level and energy consumption varied between models, two of which were multivolt (Medix Traveller and AFP TO1).

\section{Dynamic characteristics}

The pressure-flow characteristics of the compressors showed a wide range both of maximum static pressure 
Table 1. - Compressors, nebulizers, their mass, dimension, sound level, and units of electricity comsumed per year

\begin{tabular}{|c|c|c|c|c|c|c|c|c|c|}
\hline No. & Compressor & & Nebulizer & $\begin{array}{c}\text { UK } \\
\text { supplier }\end{array}$ & $\underset{\mathrm{kg}}{\text { Mass }}$ & $\begin{array}{l}\text { Dimensions } \\
\mathrm{H} \times \mathrm{D} \times \mathrm{W} \mathrm{mm}\end{array}$ & $\begin{array}{l}\text { Sound } \\
\text { level } \\
\mathrm{dB}\end{array}$ & $\begin{array}{l}\text { Energy } \\
\text { consumed } \\
\mathrm{kW} \cdot \mathrm{h}^{-1}\end{array}$ & $\begin{array}{l}\text { NAC } \\
\text { listed }\end{array}$ \\
\hline 1 & Aquillon & $\begin{array}{l}\text { A) } \\
\text { B) } \\
\text { C) }\end{array}$ & $\begin{array}{l}\text { Neb MKII } \\
\text { Ava Neb } 1780 \\
\text { Hudson }\end{array}$ & & 3.3 & $125 \times 170 \times 230$ & 65 & 30.5 & No \\
\hline 2 & Pari Inhalierboy & & Own & Pari & 2.9 & $95 \times 160 \times 205$ & 59 & 43.8 & No \\
\hline 3 & Aeroneb Standard & $\begin{array}{l}\text { A) } \\
\text { B) } \\
\text { C) }\end{array}$ & $\begin{array}{l}\text { Cirrus } \\
\text { Cirrus } \\
\text { Italian }\end{array}$ & Deva Medical & 2.1 & $115 \times 190 \times 250$ & 63 & 32.8 & No \\
\hline 4 & Aeroneb High Power & $\begin{array}{l}\text { A) } \\
\text { B) } \\
\text { C) }\end{array}$ & $\begin{array}{l}\text { Cirrus } \\
\text { Own } \\
\text { Italian }\end{array}$ & Deva Medical & 2.1 & $115 \times 190 \times 250$ & 63 & 32.8 & No \\
\hline 5 & Porta-Neb 50 & & Acorn & Medic Aid & 3.0 & $100 \times 350 \times 225$ & 61 & 73.0 & Yes \\
\hline 6 & Atomolette & & Own & Sinclair Medical & 2.5 & $235 \times 175 \times 160$ & 50 & 51.3 & Yes \\
\hline 7 & Medix 2000 & & Cirrus & Medix & 3.0 & $120 \times 375 \times 240$ & 62 & 25.6 & Yes \\
\hline 8 & Medix Traveller & & Cirrus & Medix & 4.1 & $120 \times 375 \times 240$ & 68 & 16.4 & Yes \\
\hline 9 & Medix Minor & & Cirrus & Medix & 3.2 & $155 \times 210 \times 245$ & 65 & 16.4 & No \\
\hline 10 & Pulmo-Aide & & Own & DeVilbiss & 3.1 & $200 \times 260 \times 240$ & 67 & 38.3 & Yes \\
\hline 11 & Nebu Pump & & Acorn & & 3.3 & $135 \times 165 \times 235$ & 63 & 18.1 & No \\
\hline 12 & AFP NO1 & & Microneb & AFP Medical & 2.9 & $95 \times 345 \times 215$ & 62 & 54.7 & Yes \\
\hline 13 & AFP TO1 & & Microneb & AFP Medical & 3.0 & $95 \times 345 \times 215$ & 60 & 10.9 & Yes \\
\hline 14 & Inspiron & & Minineb & AAH Medical & 3.1 & $115 \times 140 \times 240$ & 65 & 32.8 & No \\
\hline 15 & Novair II & $\begin{array}{l}\text { A) } \\
\text { B) } \\
\text { C) }\end{array}$ & $\begin{array}{l}\text { Microcirrus } \\
\text { Hudson } \\
\text { Cirrus }\end{array}$ & Intersugical & 4.9 & $96 \times 155 \times 200$ & 63 & 32.0 & Yes \\
\hline
\end{tabular}

UK suppliers are either the manufacturer of the compressor or are UK agents. Nebulizer: "Own" is made by the compressor supplier. H: height; D: depth; W: width. NAC listed: compressor listed by the National Asthma Campaign, UK.

Table 2. - Pressure and flow rate at the nebulizer, the MMAD and the percentage of particles less than $5.0 \mu \mathrm{m}$ at a fill volume of 2.5 and $5.0 \mu \mathrm{m}$

\begin{tabular}{|c|c|c|c|c|c|c|c|}
\hline \multicolumn{2}{|c|}{ Compressor/nebulizer combination } & $\begin{array}{l}\text { Pressure } \\
\mathrm{kPa}\end{array}$ & $\begin{array}{l}\text { Flow rate } \\
\mathrm{L} \cdot \mathrm{min}^{-1}\end{array}$ & \multicolumn{2}{|c|}{$2.5 \mathrm{ml}$ fill volume } & \multicolumn{2}{|c|}{$5.0 \mathrm{ml}$ fill volume } \\
\hline $1 \mathrm{~A}$ & Aquillon/Neb MKII & 185 & 7.0 & 2.6 & 82 & 2.6 & 83 \\
\hline $1 \mathrm{~B}$ & Aquillon/Ava Neb 1780 & 145 & 8.0 & 4.3 & 58 & 4.0 & 61 \\
\hline $1 \mathrm{C}$ & Aqillon/Hudson & 132 & 7.2 & 4.9 & 51 & 5.0 & 51 \\
\hline 2 & Pari Inhalierboy/Own & 135 & 4.1 & 6.5 & 36 & 6.2 & 39 \\
\hline $3 \mathrm{~A}$ & Aeroneb Standard/Cirrus & 67 & 3.9 & 6.6 & 35 & 6.7 & 35 \\
\hline $3 \mathrm{~B}$ & Aeroneb Standard/Own & 59 & 3.0 & 10.1 & 16 & 9.1 & 20 \\
\hline $3 \mathrm{C}$ & Aeroneb Standard/Italian & 62 & 3.6 & 10.2 & 21 & 10.1 & 22 \\
\hline $4 \mathrm{~A}$ & Aeroneb High Power/Cirrus & 104 & 4.8 & 7.6 & 28 & 7.7 & 28 \\
\hline $4 \mathrm{~B}$ & Aeroneb High Power/Own & 96 & 3.8 & 7.5 & 30 & 8.4 & 24 \\
\hline $4 \mathrm{C}$ & Aeroneb High Power/Italian & 99 & 4.0 & 10.0 & 21 & 9.5 & 22 \\
\hline 5 & Porta-Neb 50/Acorn & 110 & 6.2 & 4.7 & 54 & 4.5 & 56 \\
\hline 6 & Atmomlette/Own & 79 & 4.2 & 7.6 & 28 & 6.6 & 36 \\
\hline 7 & Medix 2000/Cirrus & 126 & 6.8 & 4.0 & 61 & 4.1 & 61 \\
\hline 8 & Medix Traveller/Cirrus & 126 & 7.0 & 4.1 & 61 & 4.2 & 59 \\
\hline 9 & Medix Minor/Cirrus & 104 & 6.9 & 3.9 & 62 & 4.1 & 60 \\
\hline 10 & Pulmo-Aide/Own & 113 & 5.1 & 5.9 & 42 & 6.3 & 38 \\
\hline 11 & Nebu Pump/Acorn & 90 & 5.6 & 4.7 & 55 & 5.0 & 50 \\
\hline 12 & AFP NO1/Microneb & 121 & 6.2 & 4.3 & 59 & 4.3 & 58 \\
\hline 13 & AFP TO1/Microneb & 127 & 6.4 & 4.3 & 60 & 4.3 & 60 \\
\hline 14 & Inspiron/Minineb & 71 & 5.7 & 6.8 & 35 & 6.9 & 35 \\
\hline $15 \mathrm{~A}$ & Novair II/Microcirrus & 105 & 6.7 & 7.0 & 39 & 5.4 & 48 \\
\hline $15 \mathrm{~B}$ & Novair II/Hudson & 90 & 5.8 & 6.1 & 39 & 6.1 & 39 \\
\hline $15 \mathrm{C}$ & Novair II/Cirrus & 92 & 5.8 & 4.5 & 57 & 4.2 & 59 \\
\hline
\end{tabular}

MMAD: mass median aerodynamic diameter. 
Table 3. - Compressors/nebulizer combination showing the volume output at 5, 10 and 20 min for a 2.5 and 5.0 ml fill volume

\begin{tabular}{|c|c|c|c|c|c|c|c|}
\hline & & & & Vol & $\%$ & & \\
\hline & mpressors/nebulizer combination & & 1 fill volu & & & 1 fill volu & \\
\hline & & $5 \mathrm{~min}$ & $10 \mathrm{~min}$ & $20 \mathrm{~min}$ & $5 \mathrm{~min}$ & $10 \mathrm{~min}$ & $20 \mathrm{~min}$ \\
\hline $1 \mathrm{~A}$ & Aquillon/Neb MKII & 50 & 57 & 72 & 27 & 60 & 83 \\
\hline 1B & Aquillon/Ava Neb 1780 & 32 & 48 & 72 & - & - & - \\
\hline $1 \mathrm{C}$ & Aqillon/Hudson & 25 & 33 & 50 & 24 & 50 & 57 \\
\hline 2 & Pari Inhalierboy/Own & 50 & 64 & 57 & 29 & 71 & 77 \\
\hline $3 \mathrm{~A}$ & Aeroneb Standard/Cirrus & 28 & 43 & 49 & 10 & 19 & 28 \\
\hline 3B & Aeroneb Standard/Own & 14 & 30 & 47 & 8 & 17 & 27 \\
\hline $3 \mathrm{C}$ & Aeroneb Standard/Italian & 23 & 40 & 48 & 9 & 24 & 40 \\
\hline 4A & Aeroneb High Power/Cirrus & 34 & 48 & 64 & 10 & 20 & 34 \\
\hline 4B & Aeroneb High Power/Own & 19 & 38 & 43 & 11 & 22 & 44 \\
\hline $4 \mathrm{C}$ & Aeroneb High Power/Italian & 37 & 48 & 60 & 19 & 24 & 67 \\
\hline 5 & Porta-Neb 50/Acorn & 30 & 38 & 66 & 17 & 44 & 68 \\
\hline 6 & Atmomlette/Own & 33 & 36 & 52 & 17 & 25 & 62 \\
\hline 7 & Medix 2000/Cirrus & 40 & 46 & 68 & 19 & 38 & 66 \\
\hline 8 & Medix Traveller/Cirrus & 37 & 42 & 59 & 16 & 30 & 65 \\
\hline 9 & Medix Minor/Cirrus & 32 & 44 & 67 & 17 & 26 & 65 \\
\hline 10 & Pulmo-Aide/Own & 26 & 44 & 51 & 16 & 29 & 64 \\
\hline 11 & Nebu Pump/Acorn & 30 & 46 & 65 & 16 & 30 & 58 \\
\hline 12 & AFP NO1/Microneb & 28 & 59 & 72 & 17 & 30 & 64 \\
\hline 13 & AFP TO1/Microneb & 43 & 66 & 81 & 23 & 42 & 75 \\
\hline 14 & Inspiron/Minineb & 41 & 51 & 56 & 24 & 43 & 69 \\
\hline $15 \mathrm{~A}$ & Novair II/Microcirrus & 32 & 42 & 50 & 22 & 41 & 62 \\
\hline 15B & Novair II/Hudson & 34 & 44 & 54 & 23 & 41 & 66 \\
\hline $15 \mathrm{C}$ & Novair II/Cirrus & 39 & 48 & 58 & 11 & 41 & 63 \\
\hline
\end{tabular}

For combination $1 \mathrm{~B}$ at the $5.0 \mathrm{ml}$ fill volume, no data were obtained due to persistant leaking.

(range 98-452 kPa) and of free flow (range 7.0-12.1 $\left.\mathrm{L} \cdot \mathrm{min}^{-1}\right)$. The flow rates and the pressures obtained at the nebulizers are given in table 2. Thirteen combinations had a flow rate at the nebulizer of less than $6 \mathrm{~L} \cdot \mathrm{min}^{-1}$. Flow rate $\left(\mathrm{L} \cdot \mathrm{min}^{-1}\right)$ at the nebulizer, within the range 3.0-8.0 L $\cdot \mathrm{min}^{-1}$, was positively correlated to the pressure $(\mathrm{kPa})$ at the nebulizer according to the relationship:

flow rate $=2.17+0.03$ pressure: $(\mathrm{RSD}=1.1: \mathrm{r}=0.64 ; \mathrm{p}<0.001)$

The volume of water output at 5, 10 and $20 \mathrm{~min}$ for a fill volume of 2.5 and $5.0 \mathrm{ml}$ is given in table 3 . The

a)

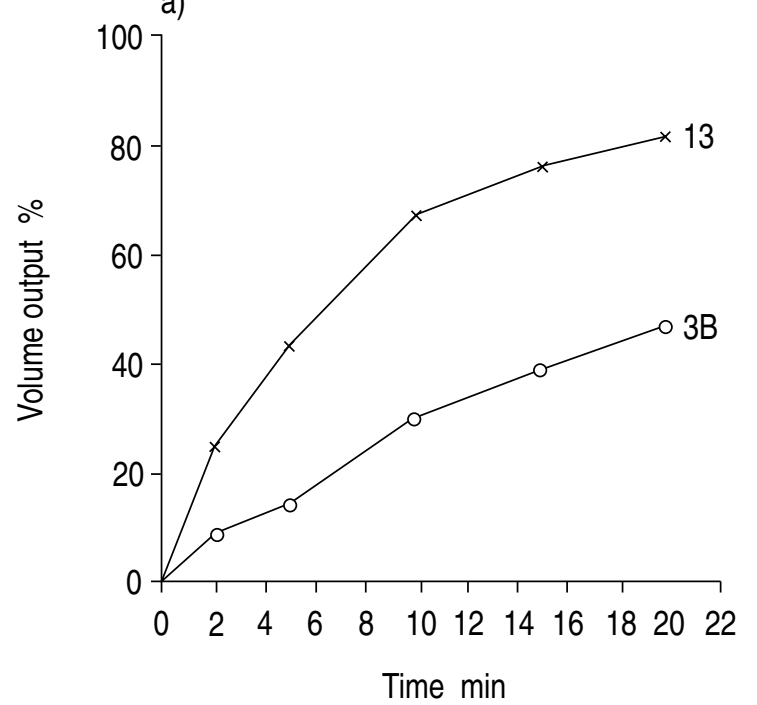

pattern of output was similar for all combinations with a $2.5 \mathrm{~mL}$ fill volume, showing a curvilinear increase up to $20 \mathrm{~min}$. For the $5.0 \mathrm{~mL}$ fill volume, the output was more varied than for the $2.5 \mathrm{~mL}$ fill volume, with the combinations having low flow rates at the nebulizer performing much worse at this fill volume. For combination $1 \mathrm{~B}$, no data were obtained at $5.0 \mathrm{~mL}$ fill volume because of persistent leaking. Examples of the relationship of volume output to time are given in figure 1 .

The volume output was still increasing at $20 \mathrm{~min}$ for both starting volumes. The mean percentage of water

b)

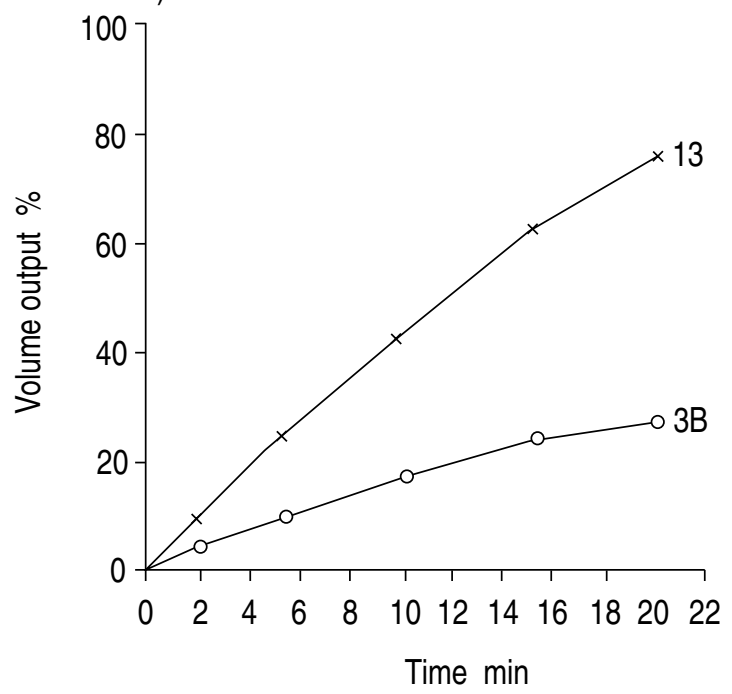

Fig. 1. - Examples of high and low volume output for a fill volume of: a) $2.5 \mathrm{~mL}$; and b) $5.0 \mathrm{~mL}$. Data are given at $2,5,10,15$ and $20 \mathrm{~min}$, for compressor nebulizer combinations $3 \mathrm{~B}(\ulcorner-\mathrm{C})$ and $13(-\times-$ See table 2 for explanation of $3 \mathrm{~B}$ and 13 . 
nebulized at 5 and $10 \mathrm{~min}$ were $33 \pm 9$ and $46 \pm 9 \%$ respectively, for the 2.5 fill volume; and $18 \pm 6 \%$ and $34 \pm 12 \%$ respectively, for the $5.0 \mathrm{~mL}$ fill volume. Five combinations (1C, 3A, 3B, 3C and 4B) failed to achieve a volume output of greater than $50 \%$ at 20 min (table 3 ). For the remaining combinations, the time needed to achieve a $50 \%$ volume output for a 2.5 and a $5.0 \mathrm{~mL}$ fill volume was $12.8 \pm 4.5$ and $14.3 \pm 3.1$ min respectively, which were not significantly different.

\section{Aerosol mass determination}

There was little variation in the MMAD for a 2.5 and $5.0 \mathrm{~mL}$ fill volume for the two combinations assessed (fig. 2). The mean MMAD was 9.7 and $9.5 \mu \mathrm{m}$ with coefficients of variation of 4.8 and $2.8 \%$ for combination $3 \mathrm{~B}$, and 4.7 and $4.6 \mu \mathrm{m}$ with coefficients of variation of 1.4 and $0.8 \%$ for combination 5 , for the 2.5 and $5.0 \mathrm{~mL}$ fill volumes, respectively.

The MMAD and the percentage of aerosol mass in particles less than $5.0 \mu \mathrm{m}$ for each combination at both fill volumes are given in table 2. Nine of the combinations had an MMAD of less than $5.0 \mu \mathrm{m}$, at either fill volume. The MMAD $(\mu \mathrm{m})$ was lower at higher flow rates at the nebulizer, and was inversely correlated to the flow rate $\left(\mathrm{L} \cdot \mathrm{min}^{-1}\right)$ at the nebulizer according to the equations:

MMAD2.5=13.0 -1.26 flow: $(\mathrm{RSD}=1.2 ; \mathrm{r}=0.83 ; \mathrm{p}<0.001)$ MMAD5.0=12.7 -1.23 flow: $(\mathrm{RSD}=1.0 ; \mathrm{r}=0.86 ; \mathrm{p}<0.001)$

Analysis of covariance showed that these equations were not significantly different and, therefore, the relationship

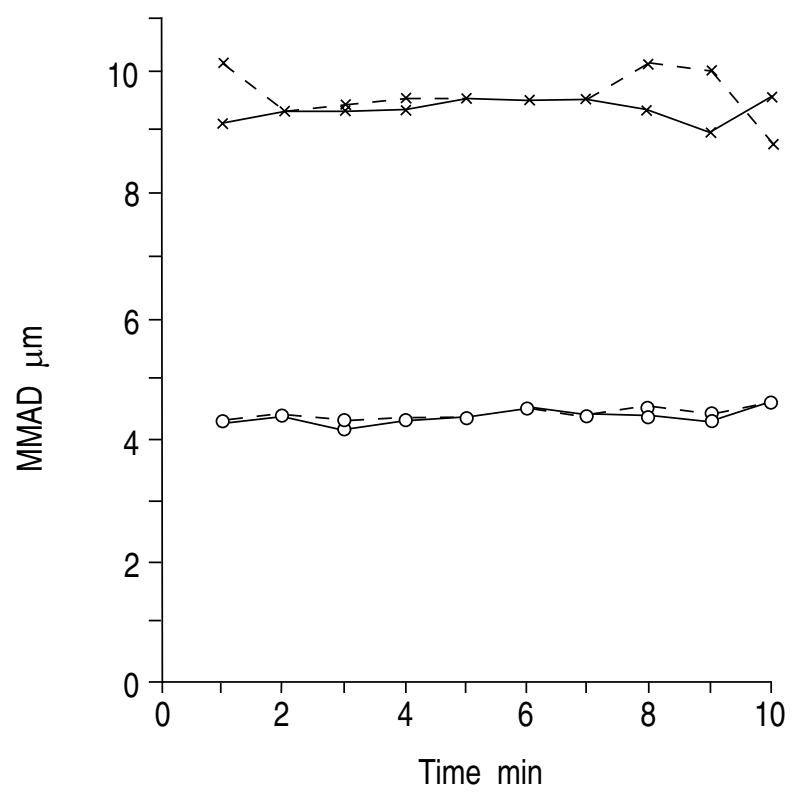

Fig. 2. - Variation over a 10 min nebulization in mass median aerodynamic diameter (MMAD) for the Aeroneb/Own and the Porta-Neb 50 combinations for 2.5 and $5.0 \mathrm{~mL}$ fill volumes. - $\mathrm{O}-$ : Porta-Neb 50, $2.5 \mathrm{~mL}$ fill volume; - - - - : Porta-Neb 5.0, $50 \mathrm{~mL}$ fill volumes; $\times$ : Aeroneb/Own, $2.5 \mathrm{~mL}$ fill volume; $-x_{-}-$: Aeroneb/Own, $5.0 \mathrm{~mL}$ fill volume. of flow rate to MMAD is independent of fill volume. To produce an MMAD of $5.0 \mu \mathrm{m}$ or less, a flow rate of $6.3 \mathrm{~L} \cdot \mathrm{min}^{-1}$ at the nebulizer is required.

The percentage of aerosol mass in particles less than $5.0 \mu \mathrm{m}$ ranged from $16-82 \%$ (mean $45 \%$ ) and $20-83 \%$ (mean $45 \%$ ), respectively, for the two fill volumes, and was independent of the fill volume. However, the percentage of aerosol mass in particles less than $5.0 \mu \mathrm{m}$ was inversely correlated to the flow rate $\left(\mathrm{L} \cdot \mathrm{min}^{-1}\right)$ at the nebulizer according to the equations:

Percent2.5=10.2 flow -11.6: $(\mathrm{RSD}=9.2 ; \mathrm{r}=0.84 ; \mathrm{p}<0.001)$ Percent2.5=10.0 flow -10.1 : $(\mathrm{RSD}=8.6 ; \mathrm{r}=0.85 ; \mathrm{p}<0.001)$

Each nebulizer/compressor combination produced its own distinctive distribution histogram of particle size, examples of which are shown in figure 3 both for 2.5 and $5.0 \mathrm{~mL}$ fill volumes.

\section{Different nebulizer/compressor combinations}

The Cirrus nebulizer was available with six different compressors (table 1), whilst four compressors were available, each with three different nebulizers. a) $2.5 \mathrm{ml}$ fill volume
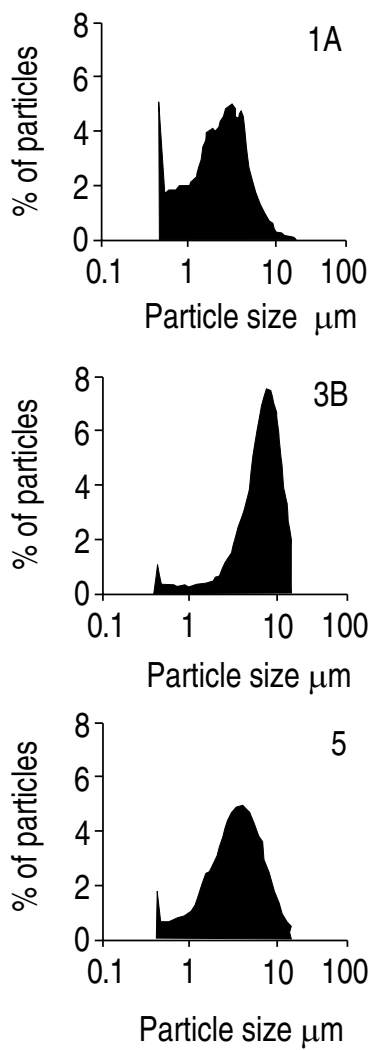

b) $5.0 \mathrm{ml}$ fill volume
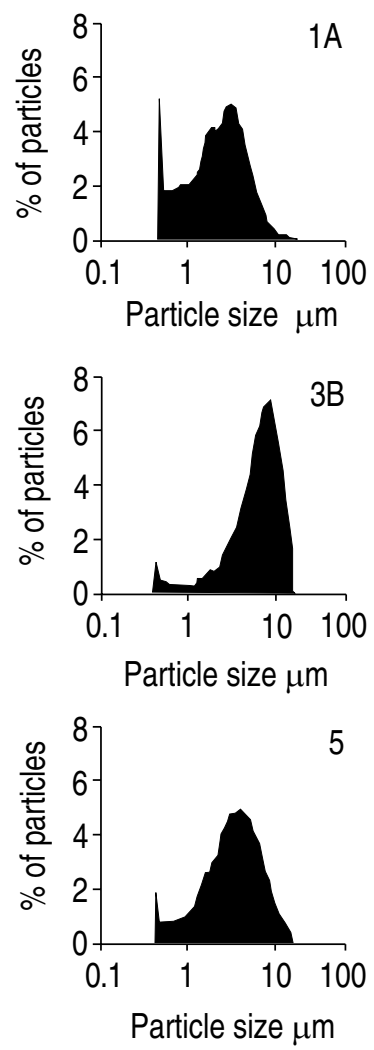

Fig. 3. - Particle size distributions for combinations $1 \mathrm{~A}, 3 \mathrm{~B}$ and 5. Each histogram represents the percentage of particles against particle size at fill volumes of: a) 2.5 ; and b) $5.0 \mathrm{~mL}$. The number in the top right hand corner of each histogram refers to the combination number in table 1 . The range $0-22.2 \mu \mathrm{m}$ accounted for approximately $97 \%$ of all particles at the 2.5 and $5.0 \mathrm{~mL}$ fill volume. 
The effect of using different compressors with the Cirrus nebulizer showed a significant relationship between flow rate $\left(\mathrm{L} \cdot \mathrm{min}^{-1}\right)$ at the nebulizer and pressure $(\mathrm{kPa})$ :

Flow rate $=0.91+0.05$ pressure: $(\mathrm{RSD}=0.8 ; \mathrm{r}=0.82 ; \mathrm{p}<0.05)$

The percentage volume nebulized at $10 \mathrm{~min}$ for the 2.5 and $5.0 \mathrm{~mL}$ fill volumes ranged from $42-48 \%$ (mean $45 \%$ ) and $19-41 \%$ (mean 29\%). The MMAD ranged from 3.9-7.7 $\mu \mathrm{m}$, and was significantly related to the flow rate $9\left(\mathrm{~L} \cdot \mathrm{min}^{-1}\right)$ at the nebulizer for both 2.5 and $5.0 \mathrm{~mL}$ fill volumes, the relationships being:

MMAD2.5=11.5 -1.1 flow: $(\mathrm{RSD}=0.8 ; \mathrm{r}=0.85 ; \mathrm{p}<0.05)$ MMAD5.0=11.5 -1.1 flow: $(\mathrm{RSD}=0.9 ; \mathrm{r}=0.82 ; \mathrm{p}<0.05)$

The flow rate at the nebulizer was not greatly different for each of the three nebulizers with the four compressors (table 2). The volume output, however, showed marked variations at 5 and $10 \mathrm{~min}$ for the combinations for the 2.5 and $5.0 \mathrm{ml}$ volume (table 3 ), whilst the MMAD showed similar marked variations at the 2.5 and $5.0 \mathrm{ml}$ fill volumes (table 2).

\section{Discussion}

This study has investigated 23 compressor/nebulizer combinations that are commercially available to the domiciliary market for the provision of inhaled therapy. The data presented is primarily related to the use of $\beta_{2^{-}}$ agonist and anticholinergic drugs and to drugs with similar densities and viscosities. The data are, therefore, not directly applicable to nebulized drugs, such as pentamidine.

Correct use of jet nebulizers depends partly on their design and operation and partly on their use by patients. Of equal importance, for domiciliary use, is the correct matching of compressor and nebulizer, since flow rate at the nebulizer and aerosol mass distribution are dependent on this matching [1]. Therapeutic aerosols such as $\beta_{2}$-agonists and anticholinergics, should ideally have an MMAD of less than $5 \mu \mathrm{m}$. However, manufacturers often simply quote a percentage of the total quantity that is smaller than a certain size. If this size is not $5 \mu \mathrm{m}$, then without information on the overall distribution of the aerosol, the effective portion of the aerosol cannot be determined. Furthermore, manufacturers often do not quote the required flow rate at the nebulizer which would produce the majority of particles under $5 \mu \mathrm{m}$.

Aerosol mass distribution is critically dependent upon the design of the baffle structures which surround the nebulizer orifice [2]. The baffles filter out the large droplets and return them for renebulization, so that any small droplets within the respirable range leave the nebulizer. The operating characteristics of the nebulizer also have an important effect on the size distributions of the aerosols released. Aerosol diameter has been shown to be inversely related to the flow rate of the gas at the nebulizer $[3,4]$, whilst the rate of aerosol output increases with the flow rate. A high flow rate at the nebulizer should, therefore, allow short patient treatment times, which should enhance patient compliance [5].

From the literature, it appears that the optimal characteristics for nebulizers are a flow rate at the nebulizer of 6-8 L·min ${ }^{-1}$, which will produce aerosols where the majority of the mass is in particles of less than $5 \mu \mathrm{m}$, together with a required high aerosol output to maximize patient compliance.

\section{Dynamic characteristics}

Pressure and flow. The dynamic characteristics for the 23 combinations varied considerably. Of the $23 \mathrm{com}-$ binations, only 10 achieved a nebulizer flow rate of greater than $6.0 \mathrm{~L} \cdot \mathrm{min}^{-1}$. The relationship between flow rate and MMAD revealed an ideal flow rate of $6.3 \pm 1.0 \mathrm{~L} \cdot \mathrm{min}^{-1}$ to produce an MMAD of $5 \mu \mathrm{m}$, suggesting that it would be possible for combinations with lower flow rates to produce an MMAD of less than $5 \mu \mathrm{m}$. This was indeed the case for combination 11 and $15 \mathrm{C}$.

Volume output. The volume output was assessed using sterile water rather than a bronchodilator drug. This was mainly for safety reasons, but also for cost. Furthermore, STEVEnTon and WiLson [1] had shown similar outputs occurred for water and salbutamol. Although different bronchodilator drugs may achieve different volume outputs, the use of sterile water as a marker of output will provide a guide to the performance of the nebulizer/compressor combination.

The volume output was generally higher at high flow rates. There was a wide variation in the percentage output at 5 and $10 \mathrm{~min}$ of nebulization both for 2.5 and 5 $\mathrm{mL}$ fill volumes. Some combinations achieved very low volume outputs and the time taken to nebulize $50 \%$ of the fill volume varied considerably.

An important distinction must be made between volume output, which is simply the total volume of solution lost from the nebulizer after a period of time, and drug output, which reflects the amount of drug that is released in the same period of time. Nebulizer output, as measured by weighing the nebulizer unit before and after activation does not reflect the actual amount of drug delivered [6-9] because some of the solution will have evaporated. Thus, weight loss is likely to overestimate the aerosol output from any combination. Drug output should be assessed using more appropriate techniques [10].

Despite the limitations of using weight loss, the technique does provide some useful information of the performance of the nebulizer/compressor system. Combinations, such as $3 \mathrm{~A}, 3 \mathrm{~B}$ and $3 \mathrm{C}$, which have long nebulization times may deter patients from using their nebulizers optimally. These patients may not, therefore, gain optimal benefit from their treatment.

\section{Particle size}

To achieve a therapeutic effect, particles of nebulized bronchodilators should have an MMAD of less than $5 \mu \mathrm{m}$. 
Larger particles $(5-100 \mu \mathrm{m})$ are principally deposited in the nasopharynx, whilst particles of less than $5 \mu \mathrm{m}$ will be predominately deposited in the lungs, including alveolar deposition [11-14]. Particles that are less than $0.5 \mu \mathrm{m}$ will reach the alveolar region with around $15 \%$ of the drug delivered being deposited [14]. This is because the method of deposition in the lung is due to gravitational effects, and the small size of the particles means that the time taken for the drug to deposit in any larger quantity is actually longer than the breathing cycle, and, therefore, the majority of the drug will be exhaled again.

Within the range 0 to $5 \mu \mathrm{m}$, small changes in particle size do not seem to be of major clinical significance [15, 16]. One study [17] using a single nebulizer has shown that only about $12 \%$ of the drug is delivered to the lung, whilst about $1 \%$ remains in the mouth. However, it is likely that these values for deposition will differ depending on the nebulizer used. Where particles are greater than $5 \mu \mathrm{m}$, greater quantities of the drug will be deposited in the buccal cavity and the nasopharynx [18-21]. To be of use, the particles of nebulized bronchodilators must then be absorbed systematically or swallowed.

We have looked at the variation in the distribution of aerosol mass for all combinations of nebulizer/compressor, using laser diffraction. This method provides a rapid source of data collection and data analysis, when compared to other methods currently available $[6,22]$. The specific information provided is that of the MMAD, the percentage of the aerosol mass in particles under $5 \mu \mathrm{m}$ and the overall distribution scattergram.

In theory, to be effective, the MMAD should be less than $5 \mu \mathrm{m}$. In this study, only 10 of the 23 combinations met this criterion, regardless of fill volume. Of more interest were the frequency distribution scattergrams for each combination at the two fill volumes. The median is the central point where half of the points are less than or equal to it and half are greater than or equal to it. Therefore, a distribution in which a large proportion of the mass is below $1.0 \mu \mathrm{m}$ will influence the MMAD value. Hence, for combination $1 \mathrm{~B}$, which had an MMAD of less than $5 \mu \mathrm{m}$, about $6 \%$ of the mass was in particles of less than $0.5 \mu \mathrm{m}$, and approximately $15 \%$ of the mass was in particles below $1.05 \mu \mathrm{m}$. This will have the effect of distorting the scattergram and, more importantly, of lowering the MMAD. Thus, it is misleading to rely on the MMAD alone. Rather the MMAD should be used with caution and in conjunction with the complete frequency distribution curve. Other information, such as the percentage of the aerosol mass in particles below $5 \mu \mathrm{m}$ is also misleading for the same reasons as quoting the MMAD. Perhaps the percentage of particles between 3 and $5 \mu \mathrm{m}$ would be more useful, since this covers the important range of particles for effective lung deposition.

An important observation was that the MMAD was not affected by the fill volume. Fill volume is generally in the range $2.5-5 \mathrm{~mL}$. Often the drug solution is diluted with normal saline. A previous study advocated a minimum fill volume of $4 \mathrm{ml}$ and an airflow rate of $6 \mathrm{~L} \cdot \mathrm{min}^{-1}$ to optimize nebuliser output [5]. However, recent evidence suggests that this will have the disadvantage of prolonging the nebulization time rather than increasing the amount of drug delivered [23]. The fact that MMAD is independent of fill volume will permit the use of fill volumes of greater than $2.5 \mathrm{~mL}$ if required to provide combined drug therapy, such as salbutamol and ipratropium, during a single nebulization. The optimum fill volume will be influenced by the residual volume.

\section{Physical characteristics}

Purchase costs are important, as some patients will have to purchase their own compressors. The cost of mains only operated devices ranged from $£ 65$ to $£ 140$, with the two multivolt options costing over $£ 100$. The annual energy consumption for 1,460 nebulizations, each of $15 \mathrm{~min}$, showed a wide variation, with four units (Nos. $8,9,11$ and 13) having an energy consumption of less than $20 \mathrm{~kW} \cdot \mathrm{h}^{-1}$. Moreover, there will be additional costs of replacement filters and nebulizer kits which are dependent on how the patient uses them, as well as the costs of an annual service to comply with national regulations. Weight and physical dimensions did not greatly differ. Sound level ranged from $50 \mathrm{~dB}$ (No. 6) up to $68 \mathrm{~dB}$ (No. 8 ). These values are in the range of a "quiet radio" (40 $\mathrm{dB})$ up to "busy street traffic" (70 dB). Where sound level is important to the patient, the quieter combinations should be considered.

\section{Different nebulizer/compressor combinations}

The importance of matching the nebulizer and compressor to achieve the optimum output performance has been previously demonstrated by STEVENTON and WILSON [1]. However, from our experience the importance of this appears to have failed to reach many users in hospitals, family practice and in the community. This study has confirmed that the correct matching of nebulizer and compressor is important to achieve the optimal performance of the system. Manufacturers must, therefore, ensure that they use an appropriate combination of nebulizer and compressor, whilst the users and the purchasers of equipment must have a greater awareness of the need to correctly match the nebulizer to the compressor. We would, therefore, advise that both the compressors and the nebulizers have clearly stated recommendations to obtain optimal performance, and that suppliers provide this information to purchasers and to users of their systems.

In conclusion, the nebulizer/compressor combinations assessed in this study, show considerable variation in overall performance. The choice of a nebulizer/compressor combination should, until further work is carried out, be based on the current recommendations for flow rate at the nebulizer and particle size. From the data in this study, only nine combinations (Nos. 1A, 1B, 1C, 5, $7,8,9,12$ and 13) satisfy both criteria of an MMAD of less than $5 \mu \mathrm{m}$ and a flow rate at the nebulizer of $6-8$ 
$\mathrm{L} \cdot \mathrm{min}^{-1}$. As regards the NAC listed systems, only five of these combinations (Nos. 5, 7, 8, 12 and 13) are included, whilst other combinations are included which do not apparently satisfy both these criteria.

Acknowledgements: The authors wish to thank the manufacturers who kindly loaned the equipment for the study, the Medical Illustration Department, Bristol Royal Infirmary for the artwork, and G. Laszlo for help and advice during the study.

\section{References}

1. Steventon RD, Wilson RDE. A guide to apparatus for home nebulisation therapy. Allen Hanburys Ltd, 1986.

2. Massey DG, Miyauchi D, Fournier-Massey G. Nebuliser function. Bull Eur Physiopathol Respir 1982; 18: 665671.

3. Clay MM, Pavia D, Newman SP, Clarke SW. Factors influencing the size distribution of aerosols from jet nebulisers. Thorax 1983; 38: 755-759.

4. Mercer TT, Goddard RF, Flores RL. Effect of auxiliary airflow on the output characteristics of compressed air nebulisers. Ann Allergy 1962; 27: 211-217.

5. Clay MM, Pavia D, Newman SP, Lennard-Jones T, Clarke SW. Assessment of jet nebulisers for lung aerosol therapy. Lancet 1983; ii: 592-594.

6. Mercer TT. Production and characterization of aerosols. Arch Intern Med 1973; 131: 39-49.

7. Wood JA, Wilson RSE, Bray C. Changes in salbutamol concentration in the reservoir solution of a jet nebulizer. Br J Dis Chest 1986; 80: 164-169.

8. O'Callaghan C, Clarke AR, Milner AD. Inaccurate calculation of drug output from nebulizers. Eur J Pediatr 1989; 148: 473-474.

9. Cockcroft DW, Hurst TS, Gore BP. Importance of evaporative water losses during standardized nebulized inhalation provocation tests. Chest 1989; 96: 505-508.

10. Dennis JH, Stenton SC, Beach JR, Avery AJ, Walters EH, Hendrick DJ. Jet and ultrasonic nebulizer output: use of a new method for direct measurement of aerosol output. Thorax 1990; 45: 728-732.

11. Lippmann M, Albert RE. The effects of particle size on the regional deposition of inhaled aerosols in the human respiratory tract. Am Ind Hyg Assoc J 1969; 30: 257-275.

12. Morrow PE. Experimental studies of inhaled materials: a basis for respiratory models. Arch Intern Med 1970; 126: 466-470.

13. Task Group on Lung Dynamics. Deposition and retention models for internal dosimetry of the human respiratory tract. Health Phys 1966; 12: 173-207.

14. Heyder J, Gebhart J, Rudolf G, Schiller CF, Stahlhofen W. Deposition of particles in the human respiratory tract in the size range $0.005-15 \mu \mathrm{m}$. J Aerosol Sci 1986; 17: 811-825.

15. Dolovich MB, Ryan G, Newhouse MT. Aerosol penetration into the lung; influence on airway response. Chest 1981; 80 (Suppl.): 834-836.

16. Ryan G, Dolovich MB, Obminski G, et al. Standardization of inhalation provocation tests: influences of nebuliser output, particle size and method of inhalation. J Allergy Clin Immunol 1981; 67: 156-161.

17. Lewis RA, Cushley MJ, Fleming JS, Tattersfield AE. Is a nebuliser less efficient than a metered dose inhaler and do pear-shaped extension tubes work? Am Rev Respir Dis 1982; 125 (Suppl.): 94.

18. Pattle RE. In. Davies CN, ed. Inhaled Particles and Vapours. New York, Pergamon Press, 1977; pp. 302-309.

19. Hounam RF, Black A, Walsh M. Deposition of aerosol particles in the nasopharyngeal region of the respiratory tract. Nature 1969; 221: 1254-1255.

20. Lippmann M, Yeates DB, Albert RE. Deposition, retention and clearance of inhaled particles. $\mathrm{Br} J$ Ind Med 1980; 37: 337-362.

21. Martens A, Jacobi W. In: Aerosole in Physik, Medizin und Tachnik, Bad Soden, Gesellschaft fur Aerosolforschung. 1974; pp.117-121.

22. Brain JD, Valberg PA. Deposition of aerosols in the respiratory tract. Am Rev Respir Dis 1979; 120: 13251374.

23. Denyer J, Dyche T, Smith EC, Kendrick AH. The optimum volume for nebulization of bronchodilators. Eur Respir J 1993; 6: (Suppl. 17): 148s. 